\title{
Nocardia exalbida sp. nov., isolated from Japanese patients with nocardiosis
}

\author{
Soji lida, ${ }^{1}$ Akiko Kageyama, ${ }^{1}$ Katsukiyo Yazawa, ${ }^{1}$ Noboru Uchiyama, ${ }^{2}$ \\ Takafumi Toyohara, ${ }^{2}$ Naohiko Chohnabayashi, ${ }^{2}$ Shin-ichi Suzuki, ${ }^{3}$ \\ Fumio Nomura, ${ }^{4}$ Reiner M. Kroppenstedt ${ }^{5}$ and Yuzuru Mikami ${ }^{1}$ \\ ${ }^{1}$ Research Center for Pathogenic Fungi and Microbial Toxicoses, Chiba University, 1-8-1 \\ Inohana, Chuo-ku, Chiba 260-8673, Japan \\ ${ }^{2}$ Division of Respiratory Medicine, St Luke's International Hospital, 9-1 Akashicho, Chuo-ku, \\ 104-8560, Tokyo, Japan \\ ${ }^{3}$ Discovery Research Laboratories, Tanabe Seiyaku Co. Ltd, 2-2-50 Kawagishi, Toda, Saitama \\ 335-8505, Japan \\ ${ }^{4}$ Department of Laboratory Medicine, Chiba University Hospital, School of Medicine, Chiba \\ University, 1-8-1 Inohana, Chuo-ku, Chiba 260-8670, Japan
}

Correspondence Yuzuru Mikami mikami@faculty.chiba-u.jp
${ }^{5}$ DSMZ - Deutsche Sammlung von Mikroorganismen und Zellkulturen, Braunschweig, Germany
Members of the genus Nocardia have been implicated as agents of infectious diseases in both immunocompetent and immunocompromised patients, but immunocompromised patients are particularly at risk (Conville et al., 2004). The primary treatment of nocardial infections in immunocompromised patients is by antibiotic therapy (Conville et al., 2004). The initial selection of antibiotic therapy should take account of the species involved as nocardial strains are known to show species-specific drug-susceptibility patterns (Mikami \& Yazawa, 1989). The most prevalent species is considered to be Nocardia farcinica (Hitti \& Wolff, 2005). However, it has been repeatedly reported that $N$. farcinica is resistant to most of the antibiotics that are typically used for the treatment of nocardial infections (Hitti \& Wolff, 2005; Kageyama et al., 2004c). Recently, the whole genome of

The GenBank/EMBL/DDBJ accession numbers for the 16S rRNA gene sequences of Nocardia exalbida strains IFM $0803^{\top}$ and IFM 10383 are $A B 187522$ and $A B 187521$, respectively.

An extended phylogenetic tree based on 16S rRNA gene sequences, the TLC mycolic acid patterns of strain IFM $0803^{\top}$ and a comparison of the physiological properties of 53 recognized Nocardia species are available as supplementary material in IJSEM Online.
$N$. farcinica was sequenced and the study revealed that this organism has more sophisticated drug-resistance mechanisms than previously thought (Ishikawa et al., 2004). These data further suggest that nocardial species determination is necessary in order to choose the most appropriate therapeutic drug. Two bacterial strains, IFM $0803^{\mathrm{T}}$ and IFM 10383, isolated from clinical specimens in Japan, were initially identified in our laboratory as Nocardia asteroides from morphological and biochemical characteristics. However, 16S rRNA gene sequencing and DNA-DNA hybridization of the two novel strains showed that they belong to a distinct species. This study was performed to determine the taxonomic position of the two novel strains using a polyphasic taxonomic approach.

Strains IFM $0803^{\mathrm{T}}$ and IFM 10383 were isolated from a bronchoalveolar lavage of a 43-year-old immunocompromised patient with lung abscess at Chiba University Hospital, Chiba, Japan, and from a 60-year-old immunocompromised patient diagnosed with pemphigus vulgaris at St Luke's International Hospital, Tokyo, Japan, respectively.

All nocardial strains used in this study were cultured on Muller Hinton II (MH II; Difco) agar slants with $1 \%$ glucose 
and $1 \%$ glycerol at $37^{\circ} \mathrm{C}$ for 1 week. Colony morphology and micromorphological properties of strains IFM $0803^{\mathrm{T}}$ and IFM 10383 were observed by light and scanning electron microscopy according to previously described procedures (Kageyama et al., 2004b). Physiological and biochemical properties were examined using published procedures (Gordon et al., 1974; Poonwan et al., 1995). Arylsulfatase activity was determined using the method of Kubica \& Beam (1961). The minimum inhibitory concentration (MIC) values for seven drugs, arbekacin, ampicillin, clarithromycin, cefetamet pivoxil cefotiam, erythromycin and a mixture of sulfamethoxazole-trimethoprim (152:8) were determined using the method described by Mikami \& Yazawa (1989). Drug susceptibility tests were performed with TRIDISK (Eiken Chemical Co.) using the method described by Kageyama et al. (2004b). Strains were stained by a modified method (Chapin \& Murray, 1999), using 0.5\% sulfuric acid for determination of acid-alcohol-fastness.

The 16S rRNA gene was amplified using PCR employing six prokaryotic $16 \mathrm{~S}$ rRNA universal primers and sequenced following procedures described previously (Kageyama et al., 2004a). Species related to the novel isolates were identified by performing a nucleotide sequence database search using BLAST programs (nucleotide-nucleotide BLAST: http:// www.ncbi.nlm.nih.gov/blast) from GenBank. Sequences of related species were also retrieved from GenBank. Nucleotide substitution rates ( $K_{\text {nuc }}$ values) were calculated (Kimura \& Ohta, 1972) and phylogenetic trees were constructed using the neighbour-joining method (Saitou \& Nei, 1987). Tree topology was evaluated using a bootstrap analysis (based on 1000 resamplings) of sequence data using CLUSTAL $\mathrm{W}$ software (Thompson et al., 1994). Sequence similarity values were determined through visual comparison and manual calculation. Genomic DNA was prepared as described previously (Kageyama et al., 2004b, c). The DNA G + C composition was estimated by HPLC (Tamaoka \& Komagata, 1984). Levels of DNA-DNA relatedness were determined using the method of Ezaki et al. (1989) using photobiotin and microplates.

Whole-cell hydrolysates were analysed for diaminopimelic acid $\left(\mathrm{A}_{2} \mathrm{pm}\right)$ isomers using TLC (Staneck \& Roberts,
1974). Whole-cell sugars were prepared according to published protocols (Lechevalier \& Lechevalier, 1980) and analysed using the TLC method (Miyadoh, 2001). Mycolic acids were prepared according to Minnikin et al. (1980). Menaquinones were analysed as described by Chun \& Goodfellow (1995). Fatty acid methyl esters were prepared and analysed as described previously using the standard Microbial Identification System (MIDI) for automated GC analysis (Sasser, 1990; Kämpfer \& Kroppenstedt, 1996).

Comparison of the almost-complete 16S rRNA gene sequences of strains IFM $0803^{\mathrm{T}}$ and IFM 10383 with those of representatives of genera classified in the suborder Corynebacterineae showed that they contained all the signature nucleotides that are expected for members of the family Nocardiaceae (Stackebrandt et al., 1997) and the genus Nocardia (Chun \& Goodfellow, 1995). Highest sequence similarities were found with Nocardia beijingensis, Nocardia arthritidis, Nocardia abscessus, Nocardia brevicatena, Nocardia paucivorans and Nocardia xishanensis, with sequence similarities of $98 \cdot 3,98 \cdot 9,98 \cdot 6,98 \cdot 4,98 \cdot 3$ and $98.9 \%$, respectively. Gene sequence similarity between strains IFM $0803^{\mathrm{T}}$ and IFM 10383 was $99 \cdot 7 \%$. A tree constructed using the neighbour-joining method depicting the phylogenetic placement of strains IFM $0803^{\mathrm{T}}$ and IFM 10383 within a subset of the genus Nocardia is shown in Fig. 1. This tree shows that the two novel strains form a monophyletic clade that is loosely associated with $N$. xishanensis JCM $12160^{\mathrm{T}}$. Sequence similarity values between strains IFM $0803^{\mathrm{T}}$ and IFM 10383 and N. xishanensis were $98 \cdot 6 \%(1367 / 1389)$ and $98 \cdot 9 \%(1396 / 1412)$.

DNA-DNA relatedness between the two novel strains and N. xishanensis was $57-59 \%$. This value is below the $70 \%$ cut-off point for species classification, as recommended by Wayne et al. (1987).

Chemotaxonomic and morphological characteristics of strains IFM $0803^{\mathrm{T}}$ and IFM 10383 were consistent with their assignment to the genus Nocardia (Goodfellow, 1998; Goodfellow et al., 1999). Both contain galactose and arabinose as characteristic whole-cell sugars and meso- $\mathrm{A}_{2} \mathrm{pm}$

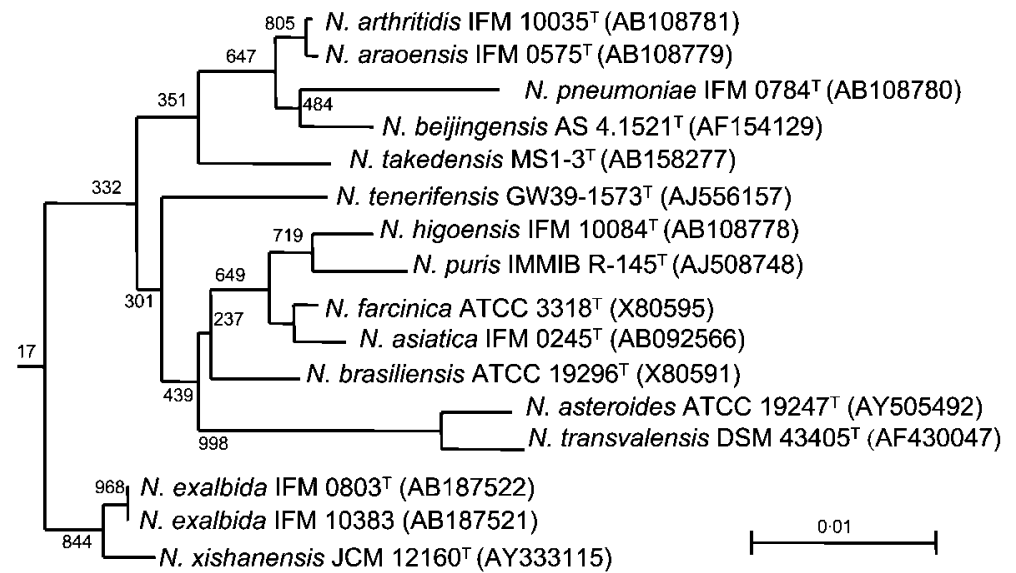

Fig. 1. Phylogenetic tree derived from $16 \mathrm{~S}$ rRNA gene sequences. The tree was created using the neighbour-joining method and $K_{\text {nuc }}$ values. Numbers at branch points indicate bootstrap values. Bar, 1 inferred substitution per 100 nucleotides. An extended tree is available as Supplementary Fig. S2 in IJSEM Online. 
as the diagnostic cell-wall diamino acid (chemotype IV sensu Lechevalier \& Lechevalier, 1980). The major menaquinone was MK-8 $(\mathrm{H} 4 \omega-\mathrm{cycl})$. The mycolic acid major chain length ranged from C48 to C56 for strains IFM $0803^{\mathrm{T}}$ and IFM 10383. TLC separation of whole-cell trans esterification extracts of strains IFM $0803^{\mathrm{T}}$ and IFM 10383 revealed two or three spots (see Supplementary Fig. S1 in IJSEM Online). The lower spot co-migrated with nocardiamycolic acids. The second spot, an unknown lipid, migrated to a position between nocardia-mycolic acid and nonhydroxylated fatty acids and the $R_{\mathrm{F}}$ value of the higher spot (third spot) correlated with non-hydroxylated fatty acids. The higher spot of strain IFM $0803^{\mathrm{T}}$ co-migrated with extracts from N. xishanensis JCM $12160^{\mathrm{T}}$ (Zhang et al., 2004). Our TLC analysis revealed the presence of the higher spot of mycolic acid in a few species of Nocardia, such as N. abscessus DSM $44432^{\mathrm{T}}, N$. beijingensis JCM $10666^{\mathrm{T}}$ and Nocardia asiatica IFM $0245^{\mathrm{T}}$ (Poonwan et al., 2005). Analyses of fatty acids of strains IFM $0803^{\mathrm{T}}$ and IFM 10383 by GLC revealed the diagnostic pattern of members of the genus Nocardia and related taxa: straight-chain saturated and unsaturated fatty acids, together with a diagnostic amount of tuberculostearic acid.

Phenotypic characteristics of the two novel strains were also examined and compared with those of recognized species of the genus Nocardia. The novel strains were able to decompose casein, but $N$. xishanensis JCM $12160^{\mathrm{T}}$ was not. N. xishanensis utilizes adipic acid, but IFM $0803^{\mathrm{T}}$ and IFM 10383 do not. Citrate is used by the novel strains, but not by $N$. xishanensis JCM $12160^{\mathrm{T}}$. Based on these phenotypic characteristics, strains IFM $0803^{\mathrm{T}}$ and IFM 10383 can be distinguished from N. xishanensis JCM $12160^{\mathrm{T}}$. The two novel strains could also be distinguished from N. xishanensis JCM $12160^{\mathrm{T}}$ on the basis of drug susceptibility tests. The differential features of the phenotypes are summarized in Table 1. A comparison of phenotypic characteristics between the two novel strains and additional species of Nocardia is available as Supplementary Table S1 in IJSEM Online. Both phenotypic and genotypic data show that the two novel isolates represent a novel species within the genus Nocardia, for which the name Nocardia exalbida sp. nov. is proposed.

\section{Description of Nocardia exalbida sp. nov.}

Nocardia exalbida (ex'al.bi.da. L. fem. adj. exalbida whitish or white, referring to the colour of the aerial mycelium).

Aerobic, Gram-positive, partially acid-fast, non-motile actinomycetes that form an extensively branched substrate mycelium that fragments into rod-shaped elements $(0 \cdot 4-0 \cdot 8 \times 0 \cdot 8-1 \cdot 7 \mu \mathrm{m})$. Orange-tan to tan colonies with abundant white to off-white aerial mycelium. No soluble pigment is produced. Colonies are $1 \cdot 0-2 \cdot 5 \mathrm{~mm}$ in diameter after 7 days at $30^{\circ} \mathrm{C}$ on MH II medium with $0 \cdot 2 \%$ glucose. Casein is decomposed, but adenine, arbutin, elastin, hypoxanthine, tyrosine and xanthine are not decomposed. Urea is decomposed. Glucose is utilized, but arabinose, erythritol, galactose, inositol, maltose, mannose, rhamnose and sorbitol are not. Citrate and testosterone are utilized,

Table 1. Phenotypic properties of strains IFM $0803^{\top}$, IFM 10383, N. xishanensis JCM $12160^{\top}$ and N. abscessus JCM 6043

+, Positive; -, negative; W, weakly positive; ND, not determined. All strains are positive for the decomposition of aesculin and urea. All strains are negative for decomposition of adenine, elastin, hypoxanthine, tyrosine and xanthine.

\begin{tabular}{|c|c|c|c|c|}
\hline Characteristic & IFM $0803^{T}$ & IFM 10383 & $\mathrm{JCM} 12160^{\mathrm{T}}$ & JCM 6043 \\
\hline Growth at $45^{\circ} \mathrm{C}$ & - & $\mathrm{W}$ & - & - \\
\hline Acid from rhamnose (Gordon test) & - & - & - & + \\
\hline \multicolumn{5}{|l|}{ Decomposition of: } \\
\hline Arbutin & - & + & + & + \\
\hline Casein & + & $\mathrm{W}$ & - & - \\
\hline \multicolumn{5}{|l|}{ Utilization of: } \\
\hline Adipic acid & - & - & + & - \\
\hline Citrate & + & + & - & + \\
\hline \multicolumn{5}{|l|}{ Susceptibility to:* } \\
\hline Arbekacin & $<2$ & $<2$ & 4 & ND \\
\hline Ampicillin & 16 & $>16$ & 4 & ND \\
\hline Clarithromycin & 1 & 2 & $<0.006$ & ND \\
\hline Cefetamet pivoxil & $0 \cdot 5$ & 1 & $0 \cdot 12$ & ND \\
\hline Cefotiam & 8 & 4 & 2 & ND \\
\hline Erythromycin & 2 & 4 & $<0.006$ & ND \\
\hline Sulfamethoxazole-trimethoprim $(152: 8)$ & $2 \cdot 4$ & $2 \cdot 4$ & $9 \cdot 5$ & ND \\
\hline
\end{tabular}

${ }^{\star}$ MIC values at $\mu \mathrm{g} \mathrm{ml}^{-1}$. 
but adipic acid, acetamide and gluconate are not. No growth at $45^{\circ} \mathrm{C}$. The $\mathrm{G}+\mathrm{C}$ content of the DNA is $68 \mathrm{~mol} \%$. Susceptible to imipenem and tobramycin (growth inhibition zone around a paper disc with $2.5 \mu \mathrm{g}$ drug per disc), moderately susceptible to kanamycin (10 $\mathrm{g}$ disc), but not susceptible to 5 -fluorouracil (30 $\mu \mathrm{g}$ disc).

The type strain, IFM $0803^{\mathrm{T}}\left(=\mathrm{NBRC} 100660^{\mathrm{T}}=\mathrm{DSM}\right.$ $44883^{\mathrm{T}}=\mathrm{JCM} 12667^{\mathrm{T}}$ ), was isolated from the bronchoalveolar lavage of a patient with lung nocardiosis in Japan.

\section{Acknowledgements}

This work was supported by a Grant-in-Aid for Scientific Research (C) from the Ministry of Education, Culture, Sports, Science and Technology of Japan (17590385) to Y.M.

\section{References}

Chapin, K. C. \& Murray, P. R. (1999). Stains. In Manual of Clinical Microbiology, pp. 1674-1686. Edited by P. R. Murray, E. J. Baron, M. A. Pfaller, F. C. Tenover \& R. H. Yolken. Washington, DC: American Society for Microbiology.

Chun, J. \& Goodfellow, M. (1995). A phylogenetic analysis of the genus Nocardia with $16 \mathrm{~S}$ rRNA gene sequences. Int J Syst Bacteriol 45, 240-245.

Conville, P. S., Brown, J. M., Steigerwalt, A. G., Lee, J. W., Anderson, V. L., Fishbain, J. T., Holland, S. M. \& Witebsky, F. G. (2004). Nocardia kruczakiae sp. nov., a pathogen in immunocompromised patients and a member of the "N. nova complex". J Clin Microbiol 42, 5139-5145.

Ezaki, T., Hashimoto, Y. \& Yabuuchi, E. (1989). Fluorometric deoxyribonucleic acid-deoxyribonucleic acid hybridization in microdilution wells as an alternative to membrane filter hybridization in which radioisotopes are used to determine genetic relatedness among bacterial strains. Int J Syst Bacteriol 39, 224-229.

Goodfellow, M. (1998). Nocardia and related genera. In Topley and Wilson's Microbiology and Microbial Infections, 9th edn, vol. 2, Systematic Bacteriology, pp. 463-489. Edited by A. Balows \& B. I. Duerden, London: Arnold.

Goodfellow, M., Isik, K. \& Yates, E. (1999). Actinomycete systematics: an unfinished synthesis. Nova Acta Leopold 312, 47-82.

Gordon, R. E., Barnett, D. A., Handerhan, J. E. \& Pang, C. H.-N. (1974). Nocardia coeliaca, Nocardia autotrophica, and the nocardin strain. Int J Syst Bacteriol 24, 54-63.

Hitti, W. \& Wolff, M. (2005). Two cases of multidrug-resistant Nocardia farcinica infection in immunosuppressed patients and implications for empiric therapy. Eur J Clin Microbiol Infect Dis 24, 142-144.

Ishikawa, J., Yamashita, A., Mikami, Y., Hoshino, Y., Kurita, H., Hotta, K., Shiba, T. \& Hattori, M. (2004). The complete genomic sequence of Nocardia farcinica IFM 10152. Proc Natl Acad Sci U S A 101, 14925-14930.

Kageyama, A., Torikoe, K., Iwamoto, M. \& 7 other authors (2004a). Nocardia arthritidis sp. nov., a new pathogen isolated from a patient with rheumatoid arthritis in Japan. J Clin Microbiol 42, 2366-2371.

Kageyama, A., Poonwan, N., Yazawa, K., Mikami, Y. \& Nishimura, K. (2004b). Nocardia asiatica sp. nov., isolated from patients with nocardiosis in Japan and clinical specimens from Thailand. Int J Syst Evol Microbiol 54, 125-130.
Kageyama, A., Yazawa, K., Ishikawa, J., Hotta, K., Nishimura, K. \& Mikami, Y. (2004c). Nocardial infections in Japan from 1992 to 2001, including the first report of infection by Nocardia transvalensis. Eur J Epidemiol 19, 383-389.

Kämpfer, P. \& Kroppenstedt, R. M. (1996). Numerical analysis of fatty acid patterns of coryneform bacteria and related taxa. Can J Microbiol 42, 989-1005.

Kimura, M. \& Ota, T. (1972). On the stochastic model for estimation of mutational distance between homologous proteins. J Mol Evol 2, 87-90.

Kubica, G. P. \& Beam, R. E. (1961). The arylsulfatase activity of acid-fast bacilli. II. The differentiation of Mycobacterium avium from the unclassified group III nonphoto chromogenic mycobacteria. Am Rev Resp Dis 83, 733-736.

Lechevalier, M. P. \& Lechevalier, H. A. (1980). The chemotaxonomy of actinomycetes. In Actinomycete Taxonomy, pp. 227-291. Edited by A. Dietz \& D. W. Thayer. Fairfax, VA: Society for Industrial Microbiology.

Mikami, Y. \& Yazawa, K. (1989). Susceptibility patterns of pathogenic Nocardia to some selected antimicrobial agents and their usefulness in the identification work in a clinical laboratory. Bull JFCC 5, 89-95.

Minnikin, D. E., Hutchinson, I. G., Caldicott, A. B. \& Goodfellow, M. (1980). Thin-layer chromatography of methanolysates of mycolic acid-containing bacteria. J Chromatogr 188, 221-233.

Miyadoh, M. (2001). Identification procedure at the genus level. In Identification Manual of Actinomycetes, pp. 9-19. Edited by S. Miyadoh, M. Hamada, K. Hotta, T. Kudo, A. Seino, K. Suzuki \& A. Yokota. Tokyo: Business Center for Academic Societies Japan.

Poonwan, N., Kusum, M., Mikami, Y., Yazawa, K., Tanaka, K., Gonoi, T., Hasegawa, S. \& Konyama, K. (1995). Pathogenic Nocardia isolated from clinical specimens including those of AIDS patients in Thailand. Eur J Epidemiol 11, 507-512.

Poonwan, N., Mekha, N., Yazawa, K., Thunyaharn, S., Yamanaka, A. \& Mikami, Y. (2005). Characterization of clinical isolates of pathogenic Nocardia strains and related actinomycetes in Thailand from 1996 to 2003. Mycopathologia 159, 361-368

Saitou, N. \& Nei, M. (1987). The neighbor-joining method: a new method for reconstructing phylogenetic trees. Mol Biol Evol 4, 406-425.

Sasser, M. (1990). Identification of bacteria by gas chromatography of cellular fatty acids. USFCC Newsl 20, 1-6.

Stackebrandt, E., Rainey, F. A. \& Ward-Rainey, N. L. (1997). Proposal for a new hierarchic classification system, Actinobacteria classis nov. Int J Syst Bacteriol 47, 479-491.

Staneck, J. L. \& Roberts, G. D. (1974). Simplified approach to identification of aerobic actinomycetes by thin-layer chromatography. Appl Microbiol 28, 226-231.

Tamaoka, J. \& Komagata, K. (1984). Determination of DNA base composition by reversed-phase high-performance liquid chromatography. FEMS Microbiol Lett 25, 125-128.

Thompson, J. D., Higgins, D. G. \& Gibson, T. J. (1994). CLUSTAL W: improving the sensitivity of progressive multiple sequence alignment through sequence weighting, position-specific gap penalties and weight matrix choice. Nucleic Acids Res 22, 4673-4680.

Wayne, L. G., Brenner, D. J., Colwell, R. R. \& 9 other authors (1987). International Committee on Systematic Bacteriology. Report of the ad hoc committee on reconciliation of approaches to bacterial systematics. Int J Syst Bacteriol 37, 463-464.

Zhang, J., Liu, Z. \& Goodfellow, M. (2004). Nocardia xishanensis sp. nov., a novel actinomycete isolated from soil. Int J Syst Evol Microbiol 54, 2301-2305. 